\title{
Prevalência de violência entre alunos nas escolas públicas do Piauí, Brasil
}

\author{
Prevalence of violence among students in public schools in Piauí, Brazil
}

\section{Prevalencia de violencia entre estudiantes de escuelas públicas en Piauí, Brasil}

\author{
Ellery Henrique Barros da Silva ${ }^{1}$, ORCID 0000-0001-5362-611X \\ Fauston Negreiros ${ }^{2}$, ORCID 0000-0003-2046-8463 \\ Ricardo Neves Couto ${ }^{3}$, ORCID 0000-0001-9989-4857 \\ ${ }^{1}$ Universidade Federal do Piauí, Brasil \\ ${ }^{2}$ Universidade Federal do Piauí, Brasil \\ ${ }^{3}$ Universidade Federal do Piauí, Brasil
}

Resumo: O presente trabalho tem como objetivos identificar a prevalência de violência na perspectiva do aluno, reunindo evidências de validade fatorial e precisão do questionário de violência nas escolas públicas no Piauí, no Brasil; compara, também, as pontuações quanto ao sexo dos participantes. Trata-se de um estudo do tipo documental, de abordagem quantitativa. Os documentos de registros das 21 GRE somaram 57.906. Após a coleta, foi possível analisar a estrutura fatorial das perguntas referentes ao questionário de violência por meio de uma análise de frequência, seguida de uma análise fatorial exploratória, de uma análise paralela de confiabilidade e teste $t$ para comparação em relação ao sexo. Os resultados sugerem uma estrutura interna do questionário unifatorial, com índices psicométricos satisfatórios, além de indicarem que dentre as violências mais frequentes estavam a violência verbal, seguidas da violência moral, violência material e violência social. Quanto aos participantes, o sexo masculino obteve a maior pontuação em expressões de violência na escola.

Palavras-chave: violência escolar; escolas públicas; análise fatorial; Piauí.

Abstract: The present work aims to identify the prevalence of violence from the student's perspective; gather evidence of factorial validity and precision of the violence questionnaire in public schools in Piauí, in Brazil; and compare the scores according to the participants' sex. This is a documentary type study, with a quantitative approach. The registration documents of the 21 GREs totaled 57.906. After the collection, it was possible to analyze the factorial structure of the items referring to the violence questionnaire, through a frequency analysis, followed by an exploratory factor analysis, a parallel analysis and reliability and $t$ test for comparison in relation to sex. The results suggest an internal structure of the unifactorial questionnaire, with satisfactory psychometric indices, in addition to indicating that among the most frequent types of violence were verbal violence, followed by moral violence, material violence and social violence. As for the participants, males had the highest score in expressions of violence at school.

Keywords: school violence; public schools; factor analysis; Piauí. 
Resumen: El presente trabajo tiene como objetivo identificar la prevalencia de la violencia desde la perspectiva del estudiante; reunir evidencias de validez factorial y precisión del cuestionario de violencia en escuelas públicas en Piauí, Brasil; y comparar los puntajes para el sexo de los participantes. Este es un estudio de tipo documental, con un enfoque cuantitativo. Los documentos de registro de las 21 GRE sumaron 57.906. Después de la recolección, fue posible analizar la estructura factorial de las preguntas referidas al cuestionario de violencia, a través de un análisis de frecuencia, seguido de un análisis factorial exploratorio, un análisis paralelo y una prueba de confiabilidad y $t$ para comparar en relación al sexo. Los resultados sugieren una estructura interna del cuestionario unifactorial, con índices psicométricos satisfactorios, además de indicar que entre los tipos de violencia más frecuentes se encuentran la violencia verbal, seguida de la violencia moral, la violencia material y la violencia social. En cuanto a los participantes, los varones obtuvieron la puntuación más alta en expresiones de violencia en la escuela.

Palabras clave: violencia escolar; escuelas públicas; análisis factorial; Piauí.

Recebido: 23/05/2020

Aceito: 08/10/2021

Como citar:

Barros da Silva, E. H., Negreiros, F. \& Couto, R. N. (2021). Prevalência de violência entre alunos nas escolas públicas do Piauí, Brasil. Ciencias Psicológicas, 15(2), e-2180. doi: https://doi.org/10.22235/cp.v15i2.2180

Correspondência: Ellery Henrique Barros da Silva, Universidade Federal do Piauí, Brasil. E-mail: elleryhenrique@gmail.com

A violência é constituída como um problema social que emerge por meio das variadas relações estabelecidas na sociedade. $\mathrm{Na}$ antiguidade, as práticas de violência exercidas tinham características ligadas ao modo de viver dos indivíduos e das relações estabelecidas com o seu meio social. Fatores como a cultura, a política, a religião e a economia tornam-se os principais desencadeadores da produção e da reprodução da violência em todos os espaços sociais (Magalhães \& Santos, 2016; Souza, 2019).

Na literatura internacional, a violência é entendida como um fenômeno multifacetado que se classifica a partir das ações exercidas pelos indivíduos, grupos, culturas, nações e etnias, e que se desdobra em violência física, emocional e simbólica - de forma individual ou coletiva (Conselho Federal de Psicologia, 2018).

Muitos estudos definem que a violência não pode ser compreendida apenas como sinônimo de agressividade, pois ela pode se manifestar por meio de atos velados, preconceituosos, racistas, ou seja, de forma multicausal, entre as várias formas possíveis de violência (Abramovay, 2005; Conselho Federal de Psicologia, 2018; Salles \& Silva, 2008). Desse modo, a violência enquanto fenômeno global se manifesta nos mais variados 
ambientes sociais e tem se consolidado no ambiente escolar, local seguro de aprendizagem, relações interpessoais e transformação social (Botler, 2020).

A violência escolar é compreendida como um fenômeno que se propaga em várias ações que podem partir de professores, alunos, estudantes, funcionários ou de uma comunidade ou grupo no qual indivíduos participem. As discussões, as rixas, as brincadeiras de mau gosto, as incivilidades, a destruição do patrimônio público e os conflitos são os desencadeadores para os atos de violência (Moral Zafra, 2020; Morrone, 2016).

A violência para a Organização Mundial da Saúde é uma situação de saúde pública, responsabilidade de um estado que deveria se preocupar em dispor de segurança, de cuidados individuais e coletivos a toda a sociedade. Para essa agência, especializada em saúde, definir tal fenômeno se torna abrangente, pois se ao se analisar os elevados índices de violência decorrentes em todo o mundo percebe-se que se trata de um problema social. Segundo as estatísticas, anualmente morrem cerca de 1,6 milhão de pessoas em decorrência da violência (Krug, Dahllerg, Mercy, Zwi \& Lozano, 2002).

As mudanças sociais existentes no entorno das escolas também implicam na expansão da violência, diretamente relacionadas ao aumento da criminalidade, em especial em bairros mais periféricos e com elevados índices de pobreza e vulnerabilidade social; locais em que a presença de armas de fogo, conflitos entre gangues, tráfico de drogas entre outras características reforça essa tendência. Tais situações têm alterado diretamente e indiretamente o cenário da violência social presente na escola, modificando as relações entre docentes, discentes, gestão e comunidade (Njaine \& Minayo, 2003; Silva \& Coutinho, 2020; Teixeira \& Kassouf, 2015).

Estudos revelam que a violência escolar tem modificado a vida profissional dos professores, alunos e todos que convivem direta e indiretamente dentro do espaço escolar (Abramovay, 2005; Charlot, 2005). Dentre as principais formas de manifestação da violência escolar estão a violência na escola (ocorre dentro ou fora dos muros escolares), violência contra a escola (agressões físicas, verbais, sexuais, psicológicas, entre outras) e a violência da escola (a escola se apropria por reproduzir atos de discriminação, preconceito, rotulação e simbolismos) (Silva \& Assis, 2018).

A violência em diferentes contextos sociais e individuais torna as pessoas mais vulneráveis e suscetíveis ao sofrimento e vitimização. Dados investigados pela Organização para a Cooperação e Desenvolvimento Econômico (OCDE), no ano de 2019, demonstram que o Brasil lidera o ranking de violência contra os professores na escola. O estado de São Paulo ocupa a primeira posição, sendo que a cada dois dias um professor sofre violência em sala de aula (Martins, 2019; Winston, 2019). As circunstâncias podem indicar que ao não se apresentar uma solução para diminuição de atos de incivilidade, o Estado, ao utilizar da repressão, incentiva o aluno intimidado a se utilizar da rebeldia enquanto resposta a uma determinada situação.

No estado do Piauí, dados fornecidos pela Companhia Independente de Policiamento Escolar (CIPE), relatam que foram registrados 203 casos de violência somente na capital. Dentre tantos atos ocorridos de forma sistemática, estavam as ameaças e brigas envolvendo alunos e professores, uso de entorpecentes e porte de armas de fogo e armas branca. Em detrimento de tais ocorrências, foi implementado pelo Ministério Público o projeto Queremos $\mathrm{Paz}$, que tinha como objetivo fomentar a cultura da paz por meio do diálogo e do respeito através das diferenças (Brito, 2020). 
A violência escolar enquanto construto multifacetado vem ocupando um local de destaque nas mídias sociais, e fica evidente que atinge um elevado número de pessoas no mundo independentemente do grupo social (homem, mulher, indígena, negro, LGBTQIA+ etc.) ou classe econômica. Porém, vale ressaltar que pesquisas constatam que estudantes do sexo masculino são mais suscetíveis a serem agressores e vítimas ao invés de estudantes do sexo feminino (Sousa \& Stelko-Pereira, 2016; Vasconcelos, Holanda \& Albuquerque, 2016). Assim, é importante assinalar que ambos os sexos praticam violência e que independente da forma que cada um realiza tal ato, desenvolvem relações de poder e dominação sobre o outro.

Obras encontradas na literatura evidenciam que a violência escolar obteve um crescimento em paralelo a um baixo desempenho nos atores envolvidos no processo (vítimas, agressores e testemunhas) (Botler, 2020; Charlot, 2005). Desse modo, a violência escolar é um fenômeno multicausal, que perpassa todas as esferas sociais. Torna-se necessário saber quais as concepções, as ideias que os envolvidos (alunos e professores) possuem para que sejam promovidas ações de enfrentamento de tal incivilidade na instituição escolar e sua reprodução em outros espaços sociais (Conselho Federal de Psicologia, 2018).

Diante dessa discussão o estudo propõe como objetivo identificar a prevalência de violência na perspectiva do aluno, e reunir evidências de validade fatorial e precisão do questionário de violência nas escolas públicas no Piauí, no Brasil; além de comparar as pontuações quanto ao sexo dos participantes.

\section{Método}

\section{Natureza da Pesquisa}

Trata-se de um estudo do tipo documental de abordagem quantitativa.

\section{Documentos/ Cenário de Pesquisa}

Os documentos analisados a partir do banco de dados da Unidade de Gestão e Inspeção Escolar/UGIE da Secretaria Estadual de Educação/SEDUC somaram 57.906. A idade média dos participantes equivale 15 , sendo $(53,5 \%)$ do sexo feminino e $(46,5 \%)$ do sexo masculino. A coleta foi realizada durante o ano de 2018 e esse recorte representa (20\%), considerando o critério de inclusão ser alunos matriculados na educação básica (ensino fundamental anos finais e Ensino Médio) e técnica profissional da rede pública estadual de ensino no Piauí, no Brasil, no referido ano.

O cenário da pesquisa foram as escolas que compõem as Gerências Regionais de Educação/GRE do estado do Piauí, no Brasil. O estado é uma das 27 unidades federativas brasileiras e está limitado no noroeste da Região Nordeste. Com isso, a educação do Piauí, no Brasil, de acordo com os dados obtidos por meio da Secretaria de Estado da Educação (SEDUC) no ano de 2018, conta com mais de 340 mil estudantes matriculados em 659 escolas. Trata-se, portanto, de um dos estados brasileiros que possui os mais elevados índices de desigualdade social; sendo assim, urge fazer uma abordagem do estado, bem como da educação através das grandes regionais de educação para obter um panorama acerca de como essas gerências se articulam a respeito do levantamento da violência escolar. 


\section{Instrumentos}

Os participantes receberam um questionário elaborado pela Secretaria Estadual de Educação do Piauí (SEDUC), no Brasil, formulado com o propósito de realizar um mapeamento da violência nas escolas públicas estaduais. Os questionários foram impressos e destinados a cada uma das GREs no estado e estas, foram as responsáveis pela aplicação e coleta dos registros adquiridos no banco de dados da UGIE/SEDUC. O questionário era composto por 7 (sete) questões, totalizando 32 (trinta e dois) itens. A primeira se fundamentava em levantar quantas e quais situações de violência ocorreram ao longo das últimas semanas (por exemplo, alguém empurrou, bateu, chutou ou derrubou você; alguém ameaçou, chantageou ou intimidou você; alguém xingou, gritou ou ofendeu você). Os itens foram respondidos, e tinham algumas das seguintes possibilidades: 1x, 2ax4, $5 \mathrm{ax} 8$ ou nenhuma.

\section{Procedimentos de Coleta de Dados}

Para realização deste estudo, inicialmente foi feito contato com a UGIE/SEDUC para solicitar a autorização para ter acesso ao banco de dados dos questionários elaborados e aplicados pela SEDUC, por meio de carta de Autorização Institucional. Em seguida, a pesquisa foi submetida ao Comitê de Ética e Pesquisa (CEP) da Universidade Federal do Piauí, no Brasil, e aprovada conforme o conforme número do parecer: 3.502.770, atendendo as Resoluções N 466/2012 e N 510/2016 do Conselho Nacional de Saúde/Ministério da Saúde e com a Resolução 010/2012 do Conselho Federal de Psicologia, que versam sobre os aspectos éticos e legais de pesquisa envolvendo seres humanos.

Autorizada a realização da pesquisa, o acesso ao banco de dados foi coletado após a aprovação do comitê e a sua retirada da Unidade de Gestão e Inspeção Escolar/UGIE da Secretaria do Estado de Educação/SEDUC ocorreu por meio de coleta para um dispositivo móvel (pen drive), que por sua vez foi usado em um único computador com a finalidade de realizar essa pesquisa.

\section{Análise de Dados}

A análise dos dados foi feita por meio do programa estatístico SPSS, versão 21. A escolha pelo referido programa é devida ele analisar analiticamente dados mais complexos e amplos. Em um primeiro momento com análises descritivas, para caracterizar a amostra e frequência com a prevalência dos comportamentos de violência; na sequência, foi realizada uma análise fatorial, com o método fatoração do eixo principal, com rotação oblíqua (Promax), com os itens destinados à mensuração da violência a fim de reduzir em dimensões; posteriormente, foi comparada a pontuação dos gêneros com um teste $t$, e, por fim, a precisão das respostas dos itens foi avaliada por meio do índice de alfa de Cronbach.

\section{Resultados}

Tendo em conta os objetivos deste estudo, procurou-se organizar os resultados de modo a torná-los clara e logicamente compreensíveis pelos leitores. Neste sentido, primeiramente são apresentadas análises descritivas (tabela 1) e evidências psicométricas acerca do instrumento de violência nas escolas públicas do Piauí; e, posteriormente, a análise fatorial dos itens de violência. 
Tabela 1.

Amostra e frequência da prevalência dos comportamentos de violência

\begin{tabular}{|c|c|c|c|c|}
\hline & $\mathbf{1 x}$ & $2 \times 4$ & $5 \times 8$ & Nenhuma \\
\hline 1. Empurrar, agredir, chutar ou derrubar & $\begin{array}{c}46968 \\
(81,1 \%) \\
\end{array}$ & $\begin{array}{c}5351 \\
(9,2 \%) \\
\end{array}$ & $\begin{array}{c}3935 \\
(6,8 \%) \\
\end{array}$ & $\begin{array}{c}1652 \\
(2,9 \%) \\
\end{array}$ \\
\hline 2. Humilhar, difamar ou apelidar & $\begin{array}{c}37025 \\
(63,9 \%) \\
\end{array}$ & $\begin{array}{c}9151 \\
(15,8 \%)\end{array}$ & $\begin{array}{c}7086 \\
(12,2 \%) \\
\end{array}$ & $\begin{array}{l}4644 \\
(8 \%) \\
\end{array}$ \\
\hline 3. Ameaçar, chantagear e intimidar & $\begin{array}{c}48375 \\
(83,5 \%) \\
\end{array}$ & $\begin{array}{c}5111 \\
(8,8 \%) \\
\end{array}$ & $\begin{array}{c}3111 \\
(5,4 \%) \\
\end{array}$ & $\begin{array}{c}1309 \\
(2,3 \%) \\
\end{array}$ \\
\hline 4. Excluir ou ficar fora de um grupo & $\begin{array}{c}41947 \\
(72,4 \%)\end{array}$ & $\begin{array}{c}8577 \\
(14,8 \%)\end{array}$ & $\begin{array}{c}4919 \\
(8,5 \%)\end{array}$ & $\begin{array}{c}2463 \\
(4,3 \%) \\
\end{array}$ \\
\hline 5. Destruir ou extraviar algum objeto & $\begin{array}{c}39534 \\
(68,3 \%)\end{array}$ & $\begin{array}{c}8776 \\
(15,2 \%)\end{array}$ & $\begin{array}{c}5842 \\
(10,1 \%)\end{array}$ & $\begin{array}{c}3754 \\
(6,5 \%)\end{array}$ \\
\hline 6. Redes sociais/aplicativos para ofensas & $\begin{array}{l}52709 \\
(91 \%) \\
\end{array}$ & $\begin{array}{c}3094 \\
(5,3 \%)\end{array}$ & $\begin{array}{c}1436 \\
(2,5 \%)\end{array}$ & $667(1,2 \%)$ \\
\hline 7. Assédio ou gestos obscenos & $\begin{array}{c}45664 \\
(78,9 \%) \\
\end{array}$ & $\begin{array}{c}5406 \\
(9,3 \%) \\
\end{array}$ & $\begin{array}{c}4302 \\
(7,4 \%)\end{array}$ & $\begin{array}{c}2534 \\
(4,4 \%) \\
\end{array}$ \\
\hline 8. Xingar, gritar ou ofender & $\begin{array}{c}33521 \\
(57,9 \%)\end{array}$ & $\begin{array}{c}9996 \\
(17,3 \%)\end{array}$ & $\begin{array}{c}8918 \\
(15,4 \%)\end{array}$ & $\begin{array}{c}5471 \\
(9,4 \%)\end{array}$ \\
\hline
\end{tabular}

Diante da frequência da violência dos 8 (oito) itens do questionário de violência de cunho individual, surgiu a possibilidade de reduzi-los a dimensões/ fatores. Para tanto, foi necessário realizar uma análise fatorial exploratória (AFE) e análise de precisão, com resultados apresentados a seguir.

A fim de verificar a estrutura fatorial, realizou-se uma AFE. Para avaliar se a matriz de dados era passível de fatoração, procurou-se comprovar o índice de KMO e o Teste de Esfericidade de Bartlett. Os indicadores obtidos de adequação da amostra foram: KMO = 0,86; Bartlett $=83726,698 ; p<0,01$, mostrando a significância das correlações na matriz de dados. Utilizou-se o método fatoração do eixo principal, com rotação oblíqua (Promax), obtendo uma estrutura fatorial com dois fatores, com valores de eigenvalues acima de 1,0 esclareceu-se os 50,01\% da variância dos dados. A representação gráfica dos valores próprios (Critério de Cattell) apresentou a existência de um único fator. 


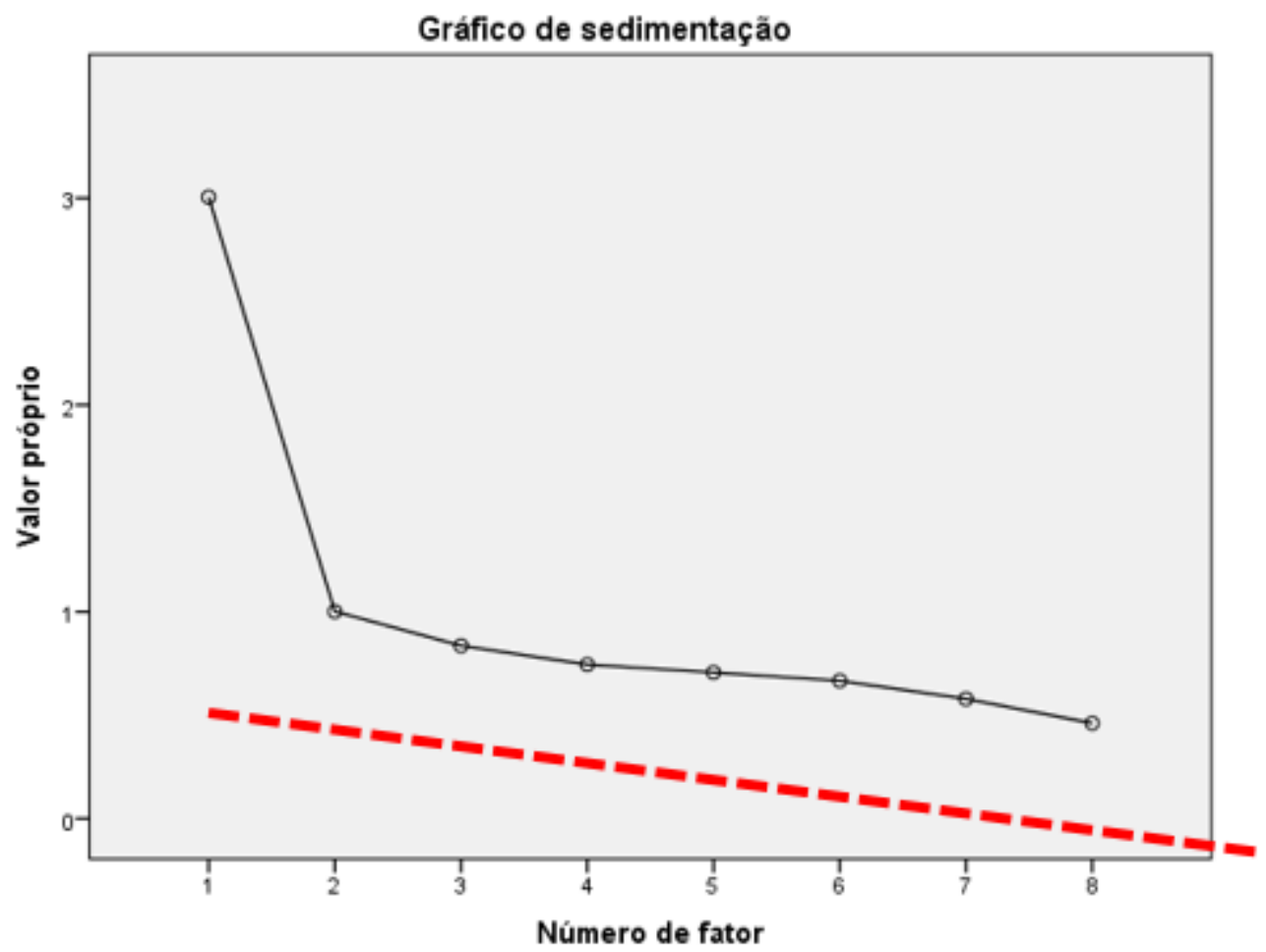

Figura 1. Representação gráfica dos valores próprios

O Critério de Kaiser apresentou dois fatores, e o de Cattell (figura 1) mostrou uma adequação com uma única dimensão. Para obter maior clareza a respeito da dimensionalidade dos itens, optou-se por realizar uma análise paralela, que permitiu a comparação dos valores dos dados reais com os dos dados aleatórios, com isso foi retirado apenas um fator no qual o autovalor dos dados reais era maior que dos dados aleatórios (tabela 2).

Tabela 2.

Resultado da Análise Paralela

\begin{tabular}{ccc}
\hline Número de fatores & Autovalor real & Autovalor aleatório \\
\hline 1 & 3,01 & 1,02 \\
2 & 1,01 & $1,02^{*}$ \\
3 & 0,84 & $1,00^{*}$ \\
4 & 0,74 & $1,003^{*}$ \\
5 & 0,71 & $1,01^{*}$ \\
6 & 0,67 & $0,99^{*}$ \\
7 & 0,58 & $0,99^{*}$ \\
8 & 0,46 & $0,98^{*}$ \\
\hline
\end{tabular}


Posteriormente, foi realizada uma segunda análise fatorial exploratória, restringindo a extração a um fator, considerando como carga fatorial mínima $|0,40|$ para que o item fosse retido no fator. Na tabela 3 a seguir são detalhados os dados sobre a estrutura fatorial do Questionário de violência, apresentando o número de itens e as cargas fatoriais.

Tabela 3.

Estrutura fatorial do Questionário de violência

\begin{tabular}{lc}
\hline Itens & Carga fatorial \\
\hline 8-Alguém xingou, gritou ou ofendeu você & $0,72^{*}$ \\
2-Alguém humilhou, difamou ou apelidou você & $0,68^{*}$ \\
5- Alguém destruiu/ extraviou ou roubou algum objeto seu & $0,63^{*}$ \\
4-Você foi excluído/ ficou fora de algum grupo & $0,56^{*}$ \\
3- Alguém ameaçou, chantageou ou intimidou você & $0,55^{*}$ \\
7- Alguém assediou ou falou algo obsceno para você & $0,53^{*}$ \\
6-Alguém usou redes sociais ou aplicativos para espalhar & $0,42^{*}$ \\
coisas ofensivas sobre você & 0,02 \\
1-Alguém empurrou, bateu, chutou ou derrubou você & 8 \\
\hline Número de itens & 4 \\
Valores próprios & $50,01 \%$ \\
Variância explicada & 0,79 \\
\hline
\end{tabular}

Como pode ser observado na tabela 3, todos os itens apresentaram cargas fatoriais acima do recomendado, com exceção do item "Alguém empurrou, bateu, chutou ou derrubou você", que apresentou carga fatorial abaixo de 0,35 , motivo pelo qual foi excluído. O questionário, portanto, ficou constituído por apenas 7 itens. Os itens apresentaram cargas fatoriais que variaram de 0,418 "Alguém usou redes sociais ou aplicativos para espalhar coisas ofensivas sobre você" a 0,722 "Alguém xingou, gritou ou ofendeu você". Quanto a consistência interna, levou-se em conta o alfa de Cronbach, que se mostrou meritório $(\alpha=$ 0,79). Em suma, tendo o item 8 eliminado, o instrumento ficou composto por um fator com 7 itens.

Utilizando o fator geral, a partir da somatória de todos os itens foi possível comparar a pontuação dos sexos com um teste $t$. Procedendo desta maneira, verificou-se que há diferenças estatisticamente significativa $(p<0,05)$ quanto às pontuações dos meninos e meninas, sugerindo que meninos apresentam maiores expressões de violência na escola.

\section{Discussão}

O presente estudo procurou identificar a prevalência de violência na perspectiva do aluno e reunir evidências de validade fatorial e precisão do questionário de violência nas escolas públicas no Piauí, no Brasil. Assim, de acordo com os resultados obtidos, dentre os tipos de violência na escola, as que foram mais frequentes, ao considerar as respostas 5 a 8 
vezes por semana, seguidas das 2 a 4 vezes por semana, foram a violência verbal (xingar, gritar ou ofender) e a moral (humilhar, difamar ou apelidar). Dessa forma, o aumento da violência vem crescendo nos últimos anos na sociedade atual, e sua incidência tem repercutido negativamente no espaço escolar.

Em um primeiro momento, a fim de reunir evidências psicométricas do questionário, observou-se validade interna, com todas as cargas fatoriais saturando acima do ponto de corte recomendado pela literatura $(|0,30|$, Pasquali, 2010), exceto o item 1 que especifica violência física e foi estatisticamente excluído. Ainda, como aponta Pasquali (2010), para além dos indicativos numéricos existe uma teoria por trás do instrumento, como também é possível que a variabilidade amostral e cultural tenha de alguma forma interferido nesse processo. Ressalta-se que as formas indiretas (e.g., verbal e relacional) se tornam as mais utilizadas, pois condutas como bater, empurrar, não são vistas como socialmente desejáveis (Berger, 2007; Rolim, 2008).

De maneira geral, o comportamento violento em suas diferentes formas ainda é presente no cotidiano escolar, os envolvidos podem ou não valorizar tais condutas, considerarem-se populares, fortes, além de se sentirem bem agredindo (Vasconcelos, Santana, Borges, Couto \& Fonsêca, 2017). O estudo confirmou o resultado de outras pesquisas que indicaram a violência verbal entre alunos e professores como a mais prevalente no espaço escolar. A presença de comportamentos violentos verbais e morais, por meio de insultos e ofensas, acabam por desequilibrar o ambiente e prejudicar o ensino, a aprendizagem e as relações (Martins 2019; Mischel \& Kitsantas, 2020; Pinto, Bezerra \& Morais, 2017).

A violência moral ou simbólica, a segunda em maior prevalência entre os estudantes do estudo, está associada a questões psicológicas sofridas pelos atores, nela estão explícitas as relações de poder abusivo, as imposições entre professor, alunos e demais profissionais da escola (Bourdieu, 1982; Silva \& Negreiros, 2019). Por isso, os xingamentos, as perseguições e as ameaças são representações dessa violência. É necessário enfatizar que, por muitas vezes, nesse tipo de violência, o aluno e o professor poderão até não saber que estão sendo alvo dessa violência (Pupo, 2007; Teng, Bear, Yang, Nie \& Guo, 2020).

Outro dado relevante nos resultados foi a frequência da violência material (destruir ou extraviar algum objeto), a terceira mais prevalente e social (excluir ou ficar fora de um grupo), a quarta de maior prevalência, e que corrobora com as ideias de estudos prévios (Mello \& Campos, 2018; Souza Batista \& Calheiros, 2020) que apontam na direção da falta de diálogo, de comunicação e a imposição autoritária por meio de práticas opressoras e que permitiram o surgimento de comportamentos que ergueram obstáculos na aprendizagem e dificuldades nas relações interpessoais.

Nesse sentido, a violência pode ter diversas manifestações, formas de produção e reprodução. Estudos apontam que a violência material está associada a condições precárias e baixa infraestrutura; a destruição do patrimônio público, as pichações e os furtos contribuem para gerar a violência nas escolas. A propósito, percebe-se que a violência escolar ocasiona diversas formas de representações e que a tendência a reproduzir é oriunda de fatores internos e externos dos mais variados ambientes sociais, como a família, a igreja, a política, a comunidade no entorno da escola, dentre outros (Pinto et al., 2017). 
A incidência da violência em todos os espaços sociais, principalmente o escolar, está mais visível cotidianamente. Por isso, os atos de exclusão, de abandono, de isolamento se caracterizam como violência social, a quarta em maior frequência de acordo com os resultados do estudo. As pesquisas atuais sobre violência escolar revelam que as relações sociais pouco estabelecidas na escola entre os alunos, os professores, os funcionários e a comunidade influenciam para a manifestação dessa violência, trazendo insegurança, baixo desenvolvimento e mudanças de comportamento (Oliveira \& Senra, 2020; Villela, 2016).

A forma como a sociedade se organiza intensifica o aumento das desigualdades existentes em todos os setores sociais. Estudiosos de áreas diversas em países no mundo sinalizam que a violência reside dentro e fora dos muros escolares, e fatores como a falta do diálogo, as divergências religiosas, os ideários políticos e as divisões de classes sociais (capital e burguesia) se tornam elementos desencadeadores da exclusão e elevação da violência social dentro desse espaço de interação e socialização (Charlot, 2005; Debarbieux, 1996; Prudente, 2017).

Já ao que se refere às quatro menos frequentes, a quinta em menor prevalência é a violência psicológica (ameaçar, chantagear e intimidar), seguida da violência sexual (assédio ou gestos obscenos) a sexta em menor frequência; já a sétima, a de menor frequência segundo a pesquisa é a violência virtual (redes sociais/aplicativos usados para ofensas) e a oitava em menor prevalência é a violência física (empurrar, agredir, chutar ou derrubar).

A violência é sabida como um dos problemas mais preocupantes na sociedade contemporânea, entretanto as variadas formas de expressão das violências variam a partir do contexto histórico-cultural de cada realidade escolar.

Contudo, é importante destacar que a literatura tem apontado que o uso das Tecnologias da Informação e Comunicação - TICs estão sendo utilizadas como formas de produção de violência, por meio do ambiente virtual, vencendo os limites dos muros escolares. Uma pesquisa desenvolvida pelo Comitê Gestor da Internet no Brasil (CGI.br) no ano de 2018 em parceria com o Centro Regional de Estudos para o Desenvolvimento da Sociedade da Informação (Cetic.br), com crianças e adolescentes de 9 a 17 anos, apresenta o cyberbullying como um dos problemas mais presentes na vida dos jovens (Coelho, 2018; Schreiber \& Antunes, 2015; Wendt \& Lisboa, 2013). Portanto, os resultados constataram que a violência virtual que deveria ser a mais frequente tornou-se a de menor prevalência entre os oito tipos de violência na escola.

As práticas de exclusão e a ampliação das desigualdades em todos os espaços sociais têm ocasionado violência, principalmente na escola. Além disso, a violência escolar também tem relação com o sexo. Ao longo da história, homens exerceram sua força e dominação contra o outro, e por uma questão cultural, em decorrência dos resquícios patriarcais, tal postura ainda é comumente transmitida para outras gerações na sociedade (Giordani, Seffner \& Dell'Aglio, 2017; Silva, Moraes \& Rocha, 2017). Em estudo realizado em 2018 com adolescentes matriculados do $6^{\circ}$ ao $9^{\circ}$ ano escolar - público afim com a presente pesquisa -, demonstrou também a maior prevalência de violência (em todos os tipos) em estudantes do sexo masculino $(33,8 \%)$, o que evidencia os resultados obtidos desta pesquisa em que os meninos possuem maiores expressões de violência na escola (Marcolino, Calvacanti, Padilha, Miranda \& Clementino, 2018). 
Os resultados do estudo demonstraram que as cargas fatoriais dos itens no fatorial geral de violência nas escolas estiveram acima de |0,40|, o que tem sido comumente exigido (Clark \& Watson, 1995; Hair, Anderson, Tatham \& Black, 2006), e o alfa de Cronbach superou o ponto de corte mais exigente $|0,70|$ (Lance, Butts \& Michels, 2006). Assim sendo, os pesquisadores interessados nessa temática dispõem de uma medida psicometricamente adequada, que tem a vantagem de contar com poucos itens.

\section{Considerações finais}

Esse estudo teve como escopo fazer a identificação da prevalência da violência na perspectiva do aluno, com comparação em relação ao sexo dos participantes, bem como reuniu evidências de validade fatorial e precisão do questionário de violência nas escolas públicas no Piauí, no Brasil. Foi possível perceber nos resultados obtidos que entre os mais frequentes estão a violência verbal (xingar, gritar ou ofender), seguidas da violência moral (humilhar, difamar ou apelidar), da violência material (destruir ou extraviar algum objeto) e da violência social (excluir ou ficar fora de um grupo). Quanto as menos frequentes estão a violência psicológica (ameaçar, chantagear e intimidar), seguida da violência sexual (assédio ou gestos obscenos), a violência virtual (redes sociais/aplicativos usados para ofensas) e a violência física (empurrar, agredir, chutar ou derrubar). Quanto ao sexo dos participantes em tais atos, ficou claro que estudantes do sexo masculino são os mais propensos a serem agressores e vítimas das violências na escola quando comparado aos números de estudantes do sexo feminino.

Dessa maneira, os resultados do presente estudo podem contribuir para a construção de políticas públicas educacionais voltadas para a formação do professor, com vistas ao fortalecimento de sua prática educativa diante da mediação de conflitos e das violências na escola; contribuir ainda com o fomento de programas educacionais direcionados aos estudantes, levando em consideração as formas de expressão de emoções, o comportamento empático e o enfrentamento das múltiplas violências prevalentes (verbal, moral, material e social) no cotidiano escolar; o subsídio de práticas coconstruídas com a rede intersetorial das comunidades escolares (CRAS, CREA, Conselho Tutelar, Universidades, centros de artes e recreações, etc.) de formação da comunidade escolar (todos os funcionários da escola, sem restrições) e da comunidade em seu entorno; e, também, contribuir com o desenvolvimento de programas de formação continuada junto aos gestores escolares abarcando a cultura de paz e o elenco de potencialidades institucionais para lidar com a prevalência de violências específicas de cada unidade escolar.

Apesar deste estudo trazer evidências panorâmicas acerca da violência nas escolas públicas do Piauí, no Brasil, é relevante considerar algumas limitações. Uma limitação que se apresenta é o recorte, pois este referiu-se a um dado documental de registro referente ao ano de 2018, de somente 1 estado e em 1 contexto histórico-cultural específico. Desse modo, recomenda-se que sejam realizados novos estudos e que possam ser de caráter longitudinal, em outros estados, outras regiões brasileiras, bem como em outros países da América Latina, por exemplo, que comparem variáveis sociodemográficas, sexo, raça, etnia, bem como estudantes da iniciativa privada. 
Por meio desse estudo, espera-se que ele possa contribuir de maneira formativa para os profissionais da educação e membros da sociedade civil preocupados com a educação. Desse modo, que sejam pensadas ações de conscientização acerca dessa temática, programas e políticas de assistência à educação envolvendo os diferentes atores sociais da comunidade escolar e de seu entorno. À vista disso, os benefícios da prevenção da violência escolar é um problema de todos, uma vez que a escola como ambiente de transformação social rege os princípios da humanização e do conhecimento.

\section{Referências}

Abramovay, M. (2005). Violencia en las escuelas: un gran desafío. Revista Iberoamericana de Educación, (38), 53-66.

Berger, K. S. (2007). Update on bullying at school: Science forgotten? Developmental review, 27(1), 90-126. doi: 10.1016/j.dr.2006.08.002

Botler, A. M. H. (2020). Juventude e escola: violência e princípios de justiça em escolares de ensino médio. Cadernos CEDES, 40(110), 26-36.

Bourdieu, P. (1982). A reprodução. Rio de Janeiro: Francisco Alves.

Brito, L. (2020). Violência nas escolas do Piauí alerta especialistas e professores. Retrieved from https://cidadeverde.com/noticias/295470/violencia-nas-escolas-do-piaui-alertaespecialistas-e-professores

Charlot, B. (2005). Prefácio. In M. Abramovay (Coord.), Cotidiano das escolas: entre violências (pp. 17-25). Brasília: Unesco.

Clark, L. A. \& Watson, D. (1995). Constructing validity: Basic issues in objective scale. Psychological Assessment, 7, 309-319. doi: 10.1037/1040-3590.7.3.309

Coelho, T. (2018). O que crianças e adolescentes fazem na Internet? Pesquisa revela 10 fatos. Recuperado de https://www.techtudo.com.br/noticias/2018/10/o-que-criancase-adolescentes-fazem-na-internet-pesquisa-revela-10-fatos.ghtml

Conselho Federal de Psicologia. (2018). Violência e preconceitos na escola: contribuições da Psicologia. Brasília: Conselho Federal de Psicologia.

Debarbieux, E. (1996). La Violence en milieu scolaire. Paris: ESF.

Giordani, J. P., Seffner, F. \& Dell'Aglio, D. D. (2017). Violência escolar: percepções de alunos e professores de uma escola pública. Psicologia Escolar e Educacional, 21(1), 103-111. doi: 10.1590/2175-3539201702111092

Hair, J. F. Jr., Anderson, R. E., Tatham, R. L. \& Black, W. C. (2006). Análise multivariada (A. S. Sant'Anna, Trad.). Porto Alegre: Bookman. doi: 10.1590/21753539201702111092

Krug, E. G., Dahlberg, L. L., Mercy, J. A., Zwi, A. B. \& Lozano, R. (2002). World report on violence and health. Geneva: OMS.

Lance, C. E., Butts, M. M. \& Michels, L. C. (2006). The sources of four commonly reported cutoff criteria: What did they really say? Organizational Research Methods, 9, 202220.

Magalhães, K. C. S. M. \& Santos, S. D. M. (2016). Expressões da violência na escola: relações paradoxais presentes nas publicações científicas brasileiras. Estudos $e$ Pesquisas em Psicologia, Rio de Janeiro, 16(1), 161-179. 
Marcolino, E. M., Calvacanti, A. L., Padilha, W. W. N., Miranda, F. A. N. \& Clementino, F. S. (2018). Bullying: prevalência e fatores associados à vitimização e à agressão no cotidiano escolar. Texto \& Contexto Enfermagem, 27(1), 1-10. doi: 10.1590/010407072018005500016

Martins, L. (2019). A cada dia, ao menos 2 professores são agredidos em escolas estaduais em SP. Recuperado de https://educacao.uol.com.br/noticias/2019/08/22/a-cada-diaao-menos-2-professores-sao-agredidos-em-escolas-estaduais-emsp.htm?cmpid=copiaecola

Mello, T. L. \& Campos, D. A. (2018). Situações de violência nas aulas de educação física e a prática pedagógica do professor. Pensar a Prática, Goiânia, 21(4). doi: 10.5216/rpp.v21i4.48285

Mischel, J. \& Kitsantas, A. (2020). Percepção dos alunos do ensino médio sobre o clima escolar, prevalência de bullying e apoio e enfrentamento social. Psicologia Social da Educação, 23(1), 51-72.

Moral Zafra, E. (2020). Factores psicosociales y conducta externalizada en adolescentes: la relevancia de los estilos parentales y las actitudes hacia la violencia escolar (tese de doutorado). Universidad de Murcia, Murcia, España.

Morrone, B. (2016). Violência atinge $42 \%$ dos alunos da rede pública. Recuperado de https://epoca.globo.com/vida/noticia/2016/03/violencia-atinge-42-dos-alunos-darede-publica.html

Njaine, K. \& Minayo, M. C. S. (2003). Violência na escola: identificando pistas para a prevenção. Revista Interface, Botucatu, 17(13), 119-134. doi: 10.1590/S141432832003000200009

Oliveira, D. R. \& Senra, L. X. (2020). Desenvolvimento sociocognitivo, suporte familiar e social em adolescentes: reflexões para a compreensão da violência escolar. Revista da SPAGESP, 21(1), 21-36.

Pasquali, L. (2010). Instrumentação psicológica: Fundamentos e práticas. Porto Alegre: Artmed.

Pinto, A. M., Bezerra, F. A. P. \& Morais, R. T. (2017). A violência na escola e as consequências para a aprendizagem da criança. Recuperado de https://www.recantodasletras.com.br/artigos-de-educacao/5885599

Prudente, A. B. (2017). A violência escolar no Brasil: conceitos, expressões e alguns determinantes (trabalho de conclusão de curso). Centro de Ciências Sociais Aplicadas, Universidade Federal de Sergipe, Brazil.

Pupo, K. R. (2007). Práticas de violência moral no interior da escola: um estudo exploratório das representações do fenômeno sob a perspectiva de gênero (dissertação de mestrado). Faculdade de Educação, Universidade de São Paulo, São Paulo, Brasil.

Rolim, M. (2008). Bullying: o pesadelo da escola, um estudo de caso e notas sobre o que fazer (dissertação de mestrado). Universidade Federal do Rio Grande do Sul, Porto Alegre, Brasil.

Salles, L. M. F. \& Silva, J. M. P. E. (2008). Diferenças, preconceitos e violência no âmbito escolar: algumas reflexões. Cadernos de Educação, Pelotas, 1(30), 149-166. doi: 10.15210/CADUC.V0I30.1768 
Schreiber, F. C. C. \& Antunes, M. C. (2015). Cyberbullying: do virtual ao psicológico. Boletim Academia Paulista de Psicologia, 35(88), 109-125.

Silva, C. F. S., Moraes, A. R. \& Rocha, K. G. S. (2017). Violência de gênero no contexto escolar: refletindo sobre estratégias de enfrentamento através da extensão universitária. Expressa Extensão, 22(2), 157-169.

Silva, E. H. B. \& Negreiros, F. (2019). Violência nas escolas: implicações, causas e efeitos no espaço escolar. In F. A. Andrade \& F. M. Chaves (Orgs.), Docência: prática e práxis (pp. 99-110). Curitiba: Appris.

Silva, F. R. \& Assis, S. G. (2018). A prevenção à violência em programas interdisciplinares que atuam em escolas brasileiras e portuguesas. Ciência \& Saúde Coletiva, 23(9), 28992908. doi: 10.1590/1413-81232018239.12422018

Silva, G. C. B. \& Coutinho, D. J. G. (2020). Um estudo sobre a violência escolar e suas consequências. Brazilian Journal of Development, 6(2), 7718-7731. doi: 10.34117/bjdv6n2-176

Sousa, M. M. M. \& Stelko-Pereira, A. C. (2016). Relações entre violência escolar, gênero e estresse em pré-adolescentes. Revista Eletrônica de Educação, 10(1), 110-127.

Souza Batista, A. \& Calheiros, A. (2020). Violência escolar-estudo de caso sobre a violência nas escolas da região metropolitana de Belo Horizonte. Revista Ciência Contemporânea, 1(5), 311-326.

Souza, L. P. (2019). Um estudo sobre a violência em escolas públicas de Campo Grande$M S$. Campo Grande: Editora Inovar.

Teixeira, E. C. \& Kassouf, A. L. (2015). Impacto da violência nas escolas paulistas sobre o desempenho acadêmico dos alunos. Economia Aplicada, 19(2), 221-240. doi: 10.1590/1413-8050/ea124436

Teng, Z., Bear, G. G., Yang, C., Nie, Q. \& Guo, C. (2020). Moral disengagement and bullying perpetration: A longitudinal study of the moderating effect of school climate. School Psychology, 35(1), 99-109. doi: 10.1037/spq0000348

Vasconcelos, D. C., Santana, I. O., Borges, L. C., Couto, R. N. \& Fonsêca, P. N. (2017). Adaptação e evidências de validade e precisão do questionário de atitude frente à violência na escola. Gerais: Revista Interinstitucional de Psicologia, 10(1), 13-24.

Vasconcelos, M. S., Holanda, V. R. \& Albuquerque, T. T. (2016). Perfil do agressor e fatores associados à violência contra mulheres. Cogitare Enferme, 21(1), 1-10.

Villela, D. C. (2016). Bullying e lei $\mathrm{n}^{\circ} 13.185$, de 6 de novembro de 2015. Revista do Ministério Público do RS, Porto Alegre, (81), 9-22.

Wendt, G. W. \& Lisboa, C. S. M. (2013). Agressão entre pares no espaço virtual: definições, impactos e desafios do cyberbullying. Seção Temática Psicologia Clínica, 25(1), 73 87. doi: 10.1590/S0103-56652013000100005

Winston, T. (2019). Brasil lidera ranking mundial de violência contra professores. Retrieved from http://www.santoandre.sp.gov.br/pesquisa/ebooks/408392.pdf

Participação dos autores: Participação dos autores: a) Planejamento e concepção do trabalho; b) Coleta de dados; c) Análise e interpretação de dados; d) Redação do manuscrito;

e) Revisão crítica do manuscrito.

E. H. B. S. contribuiu em a, b, c, d, e; F. N. em a, b, c, d, e; R. N. C. em c, e.

Editora científica responsável: Dra. Cecilia Cracco. 